\title{
ASSIS CHATEAUBRIAND/PR: EVASÃO E DINÂMICA POPULACIONAL ADVINDOS DA MODERNIZAÇÃO DA AGRICULTURA E ACESSO À TERRA
}

\author{
Everaldo Lorensetti ${ }^{1}$
}

\begin{abstract}
Resumo: Este artigo tem por objetivo tratar do tema da dinâmica populacional do município de Assis Chateaubriand, situado no Oeste do Estado do Paraná, considerando a apropriação da terra e a modernização da agricultura. A criação do município de Assis Chateaubriand em 1966 e o marketing a seu respeito, veiculado nacionalmente pelos instrumentos de mídia do Jornalista que deu o nome à cidade, atraíram migrantes das mais diversas partes do país em busca de terra. A chegada de migrantes fez com que a população do município, no censo de 1970, aparecesse como a oitava maior do Paraná, quatro anos após a sua emancipação municipal. Por meio de revisões bibliográficas e entrevistas para um levantamento qualitativo e quantitativo, com moradores que desde o início da história local ainda permanecem no município, este trabalho buscou entender por que não foi possível a permanência da maior parte das pessoas que migraram para o município, uma vez que hoje há cerca de um quarto da população registrada nos primeiros censos. Constatou-se que em vista das dificuldades de acesso à terra num primeiro momento e, posteriormente, as consequências do processo de modernização da agricultura, houve a expulsão e expropriação de muitas famílias agricultoras, as quais migraram para outras regiões do Brasil, bem como para centros urbanos e industrializados, registrando na história do recém-criado município, um dos maiores eventos de evasão populacional do campo.
\end{abstract}

Palavras chave: Assis Chateaubriand, Dinâmica populacional, Apropriação da terra, Modernização da Agricultura.

\section{ASSIS CHATEAUBRIAND/PR: EVASION AND POPULATION DYNAMICS FROM MODERNIZATION OF AGRICULTURE AND ACCESS TO EARTH}

\begin{abstract}
This article looks for comprehend the population dynamics of the Assis Chateaubriand city, located in the West of the State of Paraná, considering the land tenure and the modernization of agriculture. The creation of the Assis Chateaubriand city, in 1966, and the news broadcast nationally by Journalist's communication tools, that gave the name to the city, they attracted migrants from all over the country in search of land and work. The arrival of migrants made the population of the city appears as the eighth largest in Paraná, in the 1970 census, four years after the emancipation of the city. Through bibliographic reviews and interviews for a qualitative and quantitative research with residents who have remained in the municipality since the beginning of local history, this study sought to understand why it was not the permanence of most of the people who migrated to the city, since today there are about a quarter of the population registered in the first censuses. It was found that in view of the land access difficulties at first and, posteriorly, the consequences of agricultural modernization process. In this sense, it had an expulsion and expropriation of many families that migrated to other regions of Brazil, as well as to urban and industrialized centers, what registered in the history of the freshly created city, one of the largest events of populational withdrawal.
\end{abstract}

Key-words: Assis Chateaubriand, Population dynamics, Land tenure, Modernization of agriculture.

\section{Introdução}

A partir da criação do município de Assis Chateaubriand, na década de 1960, um grande número de pessoas começou a migrar para aquela localidade, resultando num rápido e

\footnotetext{
${ }^{1}$ Professor de Sociologia da SEED - Secretaria de Estado e Educação/PR e do IFPR - Instituto Federal do Paraná, campus Assis Chateaubriand. Graduado em Ciências Sociais pela UNIOESTE - Universidade Estadual do Oeste do Paraná, campus Toledo. Mestre em Desenvolvimento Rural Sustentável pela UNIOESTE - Universidade Estadual do Oeste do Paraná, campus Marechal Cândido Rondon.
} 
impressionante crescimento populacional. Segundo o censo demográfico do IBGE, realizado em 1970, o município aparecia no posto da oitava maior população do Paraná, apenas quatro anos após sua emancipação política.

A busca por melhores condições de vida através da aquisição de uma porção de terra se mostrava o motivo impulsionador da partida de muitos, de diversas regiões do país, em direção ao município que surgia, o qual possui terras consideradas excelentes para o plantio.

Não obstante a isso, com a ajuda das mídias do jornalista que deu o nome ao local, o fluxo de pessoas foi ainda mais intenso até meados de 1975. Assis Chateaubriand recebia muitos migrantes, em decorrência da abertura de uma das últimas fronteiras agrícolas, no caso, do Oeste do Paraná.

Contudo, não foi possível, à maioria das pessoas que chegavam, obter o tão desejado acesso à terra. E esse fato veio a ser um dos motivos fundamentais para a não permanência de muitos dos primeiros moradores de Assis. A exclusão às possibilidades de compra da terra colaborou para a expulsão de muitos que buscavam condições de viver no local.

Somado ao mencionado, a partir de meados de 1970, a modernização da agricultura surge acirrando a expulsão da mão de obra braçal dos que eram empregados nas terras dos poucos que conseguiram obter posses.

A referida modernização dificultou, também, a vida dos que eram pequenos proprietários de terras. Estes, com dificuldades em modernizar a lavoura, tiveram suas propriedades “engolidas” pelos proprietários maiores, ocasionando a expropriação de muitas famílias.

A finalidade deste artigo, portanto, é apresentar os resultados da pesquisa sobre os fatos que explicam o grande fluxo e posterior refluxo populacional de Assis Chateaubriand / PR, tomando por base a forma de apropriação da terra local e as consequências da modernização do campo.

\section{Procedimentos Metodológicos}

A pesquisa que traz os resultados sobre a dinâmica populacional de Assis Chateaubraind foi realizada em duas etapas:

A primeira delas se deu pela análise bibliográfica da histórica e, muitas vezes violenta, apropriação da terra no Brasil que, por consequência, se repetiu no Paraná e em Assis Chateaubriand.

Ainda por meio de revisão bibliográfica, buscou-se compreender os motivos do grande fluxo migratório para a cidade de Assis Chateaubriand a partir de 1960, e os efeitos das 
mudanças ocorridas no campo a partir da modernização da agricultura, bem como suas consequências, para a grande população que se instalava no município.

Por último, para confirmação dos apontamentos levantados pela revisão bibliográfica, um questionário estruturado, através do método survey, foi elaborado para buscar entender de forma quantitativa e também qualitativa, os motivos da vinda dos primeiros habitantes de Assis; as condições ou dificuldades vivenciadas pelos migrantes; os conflitos existentes pela posse da terra; as possibilidades de posse da terra para os que a buscavam; as condições de permanência da população e os motivos da saída de sua maior parte.

O referido questionário conduziu entrevistas com 14 moradores que migraram para Assis a partir da década de 1960, os quais ainda vivem no município. A análise qualitativa dos dados se deu pelo discurso dos entrevistados, sem a necessidade de software para a análise quantitativa.

Os entrevistados foram selecionados por serem de distintas ocupações laborais no município, homens e mulheres com idade próxima aos oitenta anos, objetivando visões diferenciadas sobre a dinâmica populacional do município. Alguns deles são agricultores proprietários de terras; aposentados do trabalho em empresas privadas locais; agricultores aposentados que arrendam terras; proprietários de empresas do comércio local; aposentados ou pessoas do lar que chegaram a possuir terras, ou que nunca as possuíram.

\section{A Excludente Apropriação da Terra: a Lógica que Se Repetiu em Assis Chateaubriand/PR}

Desde há muito, segundo Ianni (2004), a Terra parecia ser algo disponível a todos, como uma dádiva. Ela se apresentava, na visão do autor, como sendo o local dos meios da subsistência do homem, uma espécie de despensa, "[...] um imenso arsenal de instrumentos de trabalho. [...] nele o homem extrai os elementos indispensáveis à satisfação de necessidades tais como comer, beber, vestir-se, abrigar-se; e meios de trabalho." (2004, p. 173-174).

Porém, as porções de terras foram deixando de ser disponíveis a todos mediante uma prática predatória. Ao longo da história, a Terra foi sendo transformada em propriedades privadas, mediante a tomada de suas posses. Tal fato fez com que surgissem recorrentes conflitos entre os que tiveram possibilidades de adquiri-las e os que não tiveram as mesmas oportunidades, ou que foram excluídos e expulsos dela para dar lugar a outros. Esse processo pode ser chamado de desnaturalização, onde "[...] a terra é incorporada no processo de trabalho como objeto e meio de produção. Nesse percurso, muda de figura. É retirada da natureza, humanizada [...]. Dá-se a metamorfose da terra em mercadoria.” (IANNI, 2004, p. 174). 
Assim foi desde o início da história do Brasil, com a chegada dos colonizadores portugueses que viram dificuldade em relação à posse da terra. "Os índios eram os senhores da terra, como hoje o são os brancos [...]. Os portugueses tiveram que enfrentar um inimigo não só mais numeroso, mas melhor organizado - no sentido tribal, é óbvio [...]" (FERNANDES, 2008, p. 118). Estes, que já ocupavam o território, tiveram que lutar para mantê-lo. Tal luta resultou na morte de muitos deles, em escravidão e também na perda da sua terra.

No Brasil, os portugueses tinham a intenção de apenas explorar os recursos aqui encontrados. De acordo com Prado Júnior (2012), para os colonizadores Europeus não havia a ideia de povoar. "É o comércio que os interessa, e daí o relativo desprezo por esses territórios primitivos e vazios que formam a América.” (2012, p. 14 - 15). E pela necessidade de estabelecer a posse do novo território, começaram uma saga para convencer os patrícios a virem para o Brasil. Trazê-los para cá só poderia ocorrer à base de muitos privilégios dados, como forma de compensação pelo "esforço" realizado. A terra começava a ser distribuída entre os colonizadores portugueses como recompensa pela colonização. As capitanias hereditárias foram uma das primeiras táticas utilizadas de convencimento de ocupação do território. "As doações foram em regra muito grandes, medindo-se os lotes por muitas léguas. O que é compreensível: sobravam as terras, e as ambições daqueles pioneiros recrutados a tanto custo não se contentariam evidentemente com propriedades pequenas [...]”. (PRADO JÚNIOR, 2012, p. 33).

Na história do Paraná também é possível encontrar inúmeros conflitos ligados à posse de terras.

Um dos primeiros exemplos ficou conhecido como a Guerra do Contestado. Naquele local, que fazia divisa com o Estado de Santa Catarina “[...] a construção da ferrovia São Paulo Rio Grande do Sul, pela poderosa multinacional Brazil Railway, e a concessão governamental aos construtores de quinze quilômetros de cada lado da ferrovia para explorar madeira e ervamate [...]" (SANTOS, 2010, p. 3), desalojou à força muitos moradores que ali há muito viviam.

No norte do Estado, na década de 1950, em Jaguapitã, cerca de 1500 famílias começaram a ser expulsas das terras nas quais viviam. Os novos proprietários teriam ligação com o governo do Estado que, na época, era governado por Moysés Lupion, o qual tornou-se conhecido pelo fato de estar envolvido em muitas negociações de terras, algumas delas com indícios de ilegalidade. Segundo Paz (1991, p. 11), o governo de "Lupion foi considerado calamitoso em termos de negociatas de terras [...] reproduziu, em seu mandato, o clientelismo político que marcou a Velha República". 
Assim também foi em Porecatu, cidade vizinha de Jaguapitã, bem como no Sudoeste do Paraná, em torno da região de Francisco Beltrão, Capanema e Pato Branco. Porém, no caso da região de Capanema, segundo Oliveira (1990), não havia apenas posseiros, mas sim muitos que teriam comprado terras e, portanto, eram proprietários legítimos das áreas.

Oliveira (1990, p. 25), também menciona que "[...] toda a sorte de violência foi cometida contra os camponeses da região, arrancados violentamente das terras que estavam sendo vendidas por companhias colonizadoras, ligadas ao governador [...]”.

A lógica capitalista sobre a terra, que a transforma em mercadoria possível de ser comercializada, ou dada em troca de favores, desfaz sua natureza, isto é, de algo que poderia ser disponível a todos.

Essa lógica também teria estado presente na história de Assis Chateaubriand. Adízio Figueiredo dos Santos, foi quem dera início, de forma oficial e a partir do final da década de 1950, à abertura do território onde hoje é o município de Assis. Ele surgiu com um título de cerca de 90 mil alqueires, da chamada Gleba Santa Cruz, qual título estaria sendo contestado pela União ${ }^{2}$.

A contestação acerca das terras de Assis era motivada pela Lei $2.597^{3}$, de 12 de setembro de 1955, que dispunha sobre zonas indispensáveis à defesa do país. De acordo com o texto da referida lei, áreas de fronteiras não poderiam ser concedidas a não ser, exclusivamente, pelo interesse da União, visando entre outras coisas, a segurança nacional, o que contrapunha algumas concessões feitas no governo de Lupion.

Contudo, de acordo com Colognese (1999, p. 59), "Parte da gleba Santa Cruz fora apropriada, também, por Moysés Lupion, que a transferiu para outras colonizadoras e imobiliárias [...]”, quais terras seriam devolutas, de domínio da União.

E segundo Souto Maior (1996), com a chegada da Colonizadora Norte do Paraná, no ano de 1958, de propriedade de Oscar Martinez, o qual teria adquirido de Adízio os direitos possessórios da Gleba Santa Cruz, deu-se início à comercialização das terras locais.

Antes, porém, como o ocorrido em Jaguapitã e Porecatu, a expulsão de posseiros e até de proprietários das terras, também teria ocorrido em Assis.

\footnotetext{
${ }^{2}$ De acordo com Colognese (1999), “[...] o Estado pretendia anular os direitos possessórios dos herdeiros da Fazenda Santa Cruz ou herdeiros [...]" (1999, p. 56 - 57).

${ }^{3}$ Segundo a Lei no 2.597 (BRASIL, 1955), em seu "Art. $1^{\circ}$ É vedada, nos termos do art. 180 da Constituição, nas zonas indispensáveis à defesa do país, a prática de atos referentes à concessão de terras [...]”. E no "Art. $2^{\circ}$ É considerada zona indispensável à defesa do país a faixa interna de 150 (cento e cinquenta) quilômetros de largura, paralela à linha divisória do território nacional [...]" (Brasil, 1955).
} 
Augustinho Bukoski, que na década de 1970 fora presidente do Sindicato dos Trabalhadores Rurais de Campo Mourão, em trecho de entrevista menciona que o próprio Sindicato dos Trabalhadores Rurais de Assis Chateaubriand, que fora fundado em 12 de Setembro de 1973, teria surgido justamente como fruto das demandas de posseiros, na intenção de obterem alguma forma de proteção contra as pressões vividas em Assis Chateaubriand. Ele menciona que:

Verificamos, inclusive, que aquela terra [de Assis] era de domínio da União, titulada de uma forma errônea pelo Moysés Lupion, em 1950, e que desde aquela época, os agricultores lá estavam sendo pressionados para sair. Nós conseguimos, no governo Geisel, a desapropriação daquela área, e foi uma tristeza nossa que, quando foi desapropriado, aí houve uma intensidade de pressão por parte da família Martinez. Trabalhadores vieram denunciar pra nós que houve morte de agricultores e destruíram todas as posses para não se caracterizar uma posse naquelas áreas e, depois que foram limpas as terras, o Incra titulou, definitivamente aquelas terras para o Martinez. (BUKOSKI, 2013).

Orlando José Pires, delegado da Polícia Civil de Assis Chateaubriand no período que compreendeu os anos 1976 a 1977, comentou os fatos que teria vivido enquanto dirigente da delegacia local. Segundo ele:

Era comum aparecer corpos no Rio Piquiri, inclusive da gente achar corpos que a barriga tinha sido aberta, enfiado pedras e, com uma corda outra pedra era jogado no fundo. Isso nós achamos. Foi uma época de bastante terror que eu passei lá. [...] Medo a gente tem, mas tem que superar. Foi o que eu fiz. Agora, quando eu deixei a cidade já tava bem mais calmo, calmo mesmo, já não tinha mais problema de posseiro, quer dizer, já não tinha mais terra pra eles tomarem. O que eles tinham que fazer já tinham feito. (PIRES, 2013).

Olívio Balício, agricultor e morador de Assis Chateaubriand da época em que iniciaram os trabalhos de Adízio e, posteriormente pela Colonizadora Norte do Paraná, menciona o seguinte sobre as terras que teria adquirido:

Desde 1950, os antecessores que me venderam, eu tomei posse em 1955 até 1958, quando Adízio Figueiredo do Santos, [...] invadiu a minha área com onze jagunços e me tomou cerca de 40 alqueires entre eu e a família de Jaci Bálico. Esses jagunços estavam armados com jipe de armas, inclusive, dentre essas armas tinha metralhadoras, carabinas, revólveres e outras armas desconhecidas. (BÁLICO, 2013).

Ainda sobre os conflitos relacionados à posse da terra de Assis, alguns dos entrevistados pelo questionário desta pesquisa evitaram comentar sobre a existência de tais acontecimentos. Contudo, a maioria deles afirma que teria visto, ou ouvido falar, sobre o ocorrido. O gráfico 
abaixo (1) demonstra o percentual daqueles que apontaram conhecimento dos conflitos sobre a terra no município.

Gráfico 1 - Conhecimento sobre a existência de conflitos relacionados à posse da terra

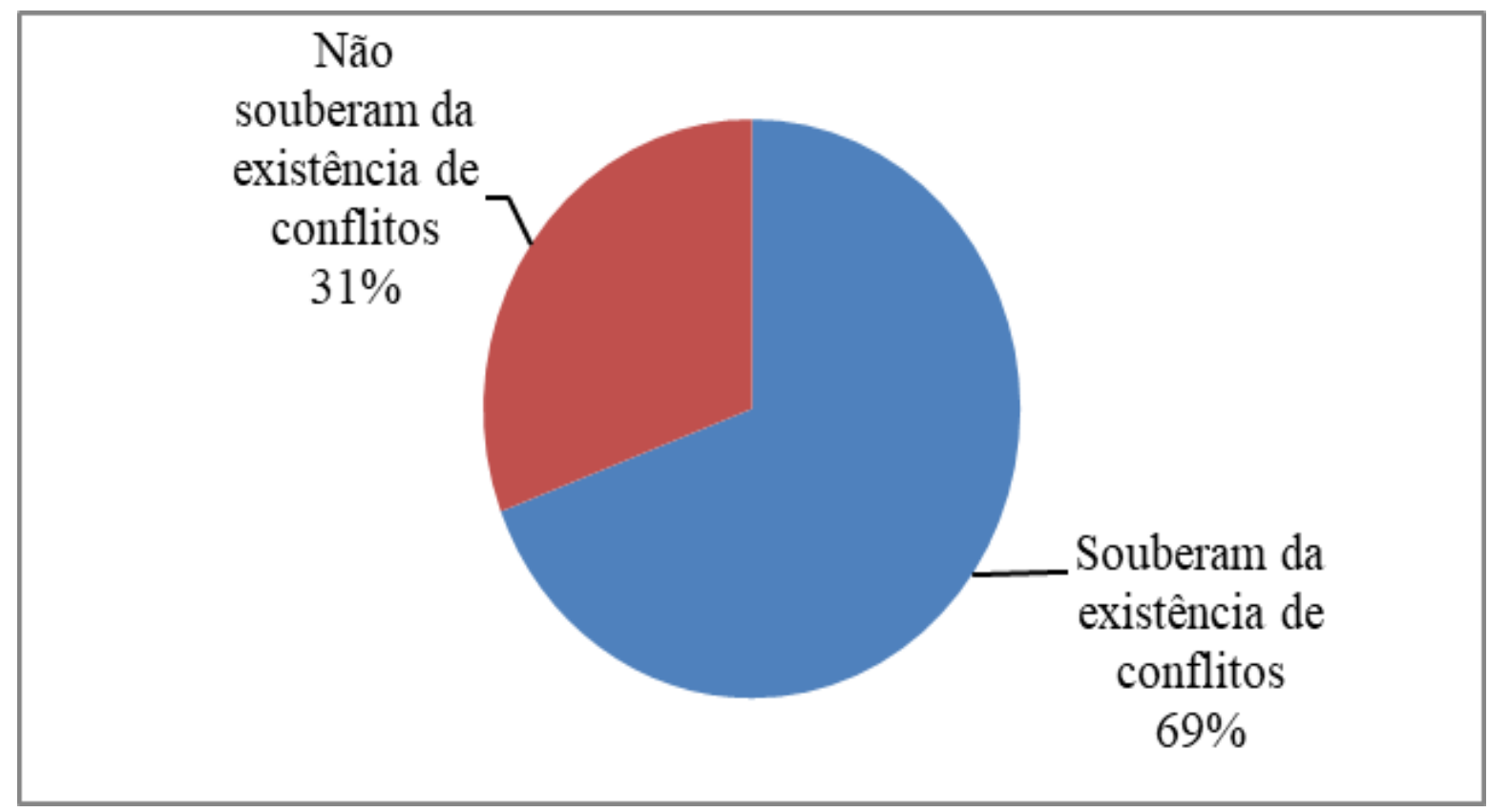

Fonte: Dados de pesquisa do autor (2017)

Apesar da existência dos depoimentos citados acima, sobre conflitos em Assis acerca da terra, inclusive com indicativo de que mortes teriam ocorrido, não foram reunidas provas que confirmassem o ocorrido e, portanto, não há ações judiciais contra os que poderiam ser acusados de expulsar, de forma violenta, vários moradores. Após alguns anos, a justiça que antes contestava as terras locais, deu causa ganha à Colonizadora Norte do Paraná, indicando que a terra deveria ser titulada definitivamente à empresa colonizadora.

\section{O fluxo Populacional de Assis Chateaubriand/PR}

Após a apropriação da terra pela Colonizadora Norte do Paraná, deu-se seguimento a um plano de comercialização das áreas locais para serem cultivadas.

A foto a seguir (fotografia 1), mostra o início do plano piloto do município que, em 1966, seria chamado de Assis Chateaubriand. 
Fotografia 1 - Assis Chateaubriand em construção na década de 1960

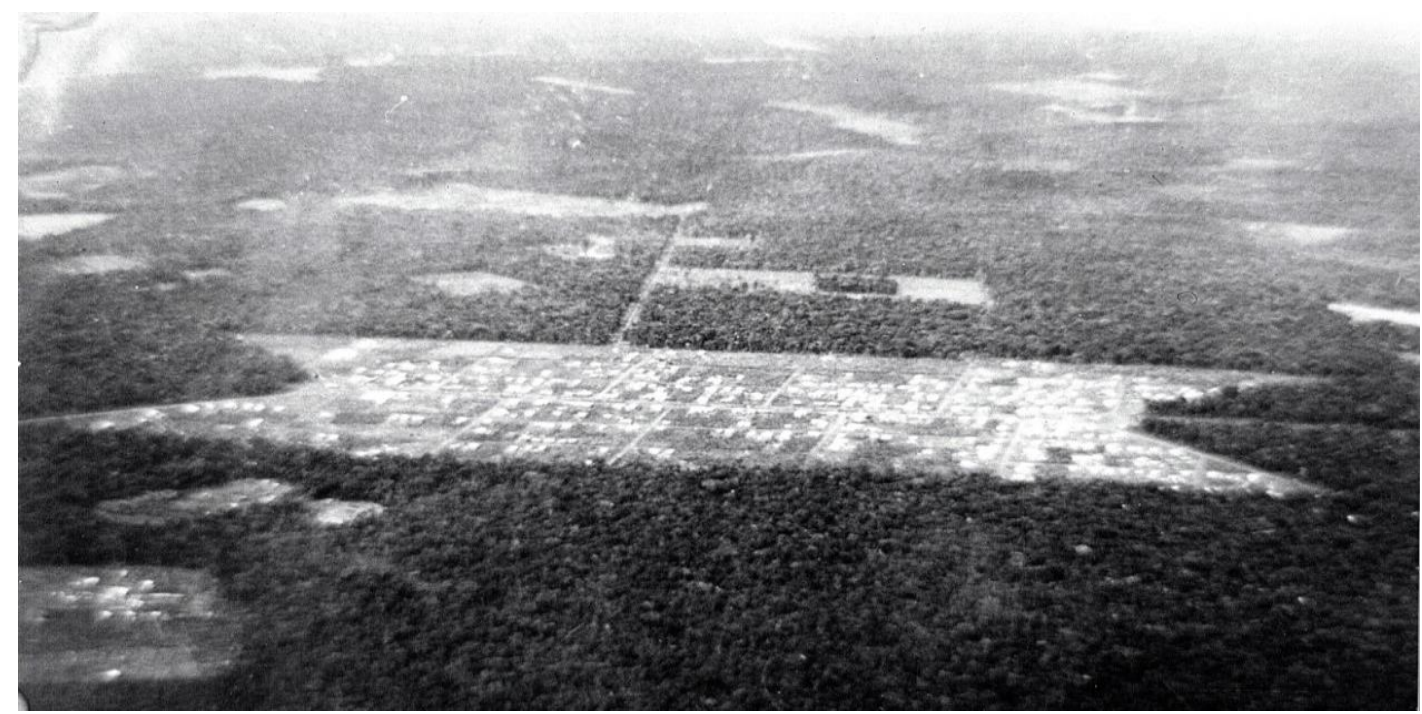

Fonte: BRITO [ca.1968]

Por ser uma localidade de terras muito férteis, Assis atraiu grande número de pessoas interessadas em adquirir propriedades para a agricultura, em pequenas ou grandes propriedades.

Segundo Souto Maior (1996, p. 125), "No início, aqui aportaram homens e mulheres de todas as partes do Brasil e do mundo. A ambição, o dinheiro, o mulherio [...] a desordem, imperavam, fazendo o município crescer demograficamente e economicamente, num galope incontido".

Em levantamento feito por Souto Maior (1996), percebe-se (figura 1) de onde vieram os muitos migrantes que compuseram a primeira população chateaubriandense.

Figura 1 - Regiões origens da população migrante de Assis

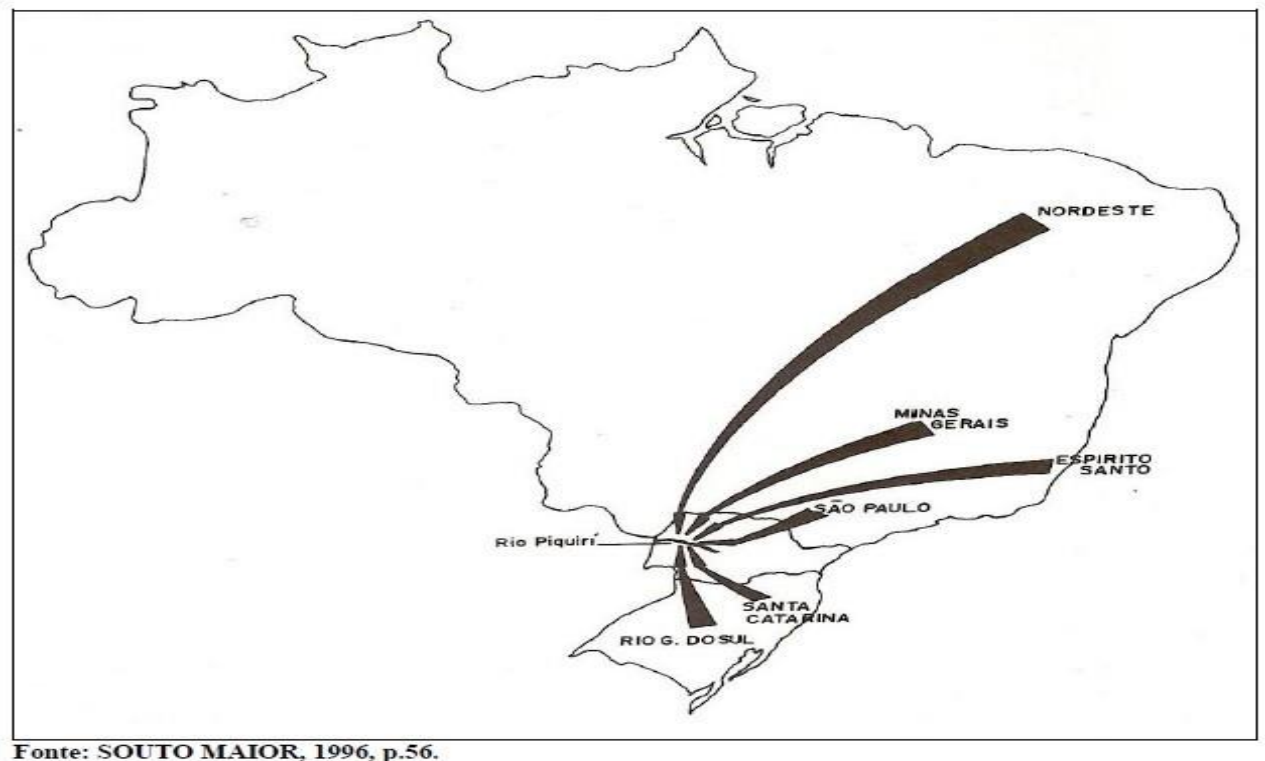


O cerne do fluxo populacional de Assis tem ligação direta com as migrações ocorridas para a abertura de uma nova fronteira agrícola no Paraná que, “[...] no Oeste trata-se de uma onda migratória oriunda de outros Estados e cidades [...]” (CRESTANI, 2012, p. 41). Assim, o crescimento populacional de Assis Chateaubriand se deu pela chegada de muitos ${ }^{4}$ que buscavam oportunidades, e eram tantos a ponto de se criar um problema de acomodação. “[...] chegava tanta gente em Assis Chateaubriand que pareciam até formigas. Eram armadas barracas com lonas até construírem seus ranchos cobertos com folhas de coqueiros." (SOUTO MAIOR, 1996, p. 299).

Pode-se dizer, portanto, que o crescimento populacional do município não foi fruto de um processo natural, também conhecido como crescimento vegetativo. Segundo Dantas (2001), o processo natural:Corresponde à diferença entre os nascimentos e óbitos; é expresso em percentagem. Assim, a taxa de crescimento vegetativo é a diferença entre a taxa de natalidade e a taxa de mortandade verificada em uma população em determinado período (geralmente um ano). Quanto maior é essa diferença, maior é o crescimento populacional. Se a diferença entre essas duas taxas for positiva, significa que a população aumentou. (DANTAS, 2001, p. 66)

Em Assis, o efeito das migrações contribuiu para a ocorrência de um crescimento horizontal, também chamado, segundo Dantas (2001, p. 67), de "migração líquida", o qual decorre da diferença entre os números de pessoas que chegam e saem de um território. Como o número dos que chegavam no município era infinitamente superior aos que saíam, a população chegou a ser uma das maiores do Paraná em meados de 1970, de acordo com a tabela abaixo (1).

Tabela 1 - Municípios mais populosos do Paraná - 1970

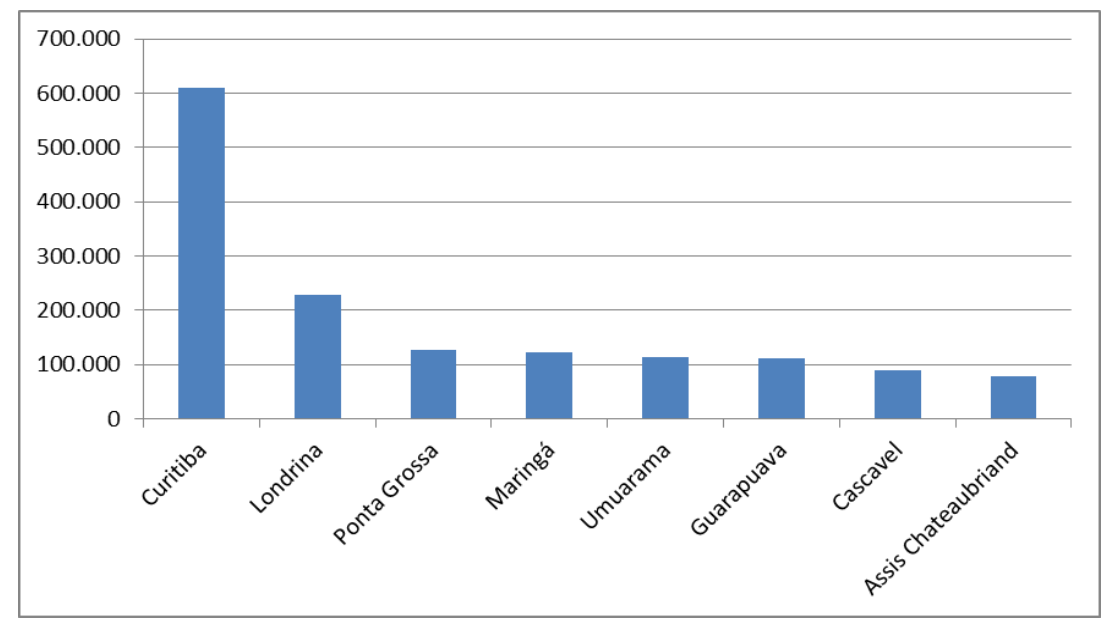

Fonte IBGE 1970.

\footnotetext{
${ }^{4}$ Segundo a edição do dia 13 de maio de 1969, do jornal "Diário de São Paulo": "Assis Chateaubriand, uma cidade do Oeste do Paraná, tem um problema muito grave e pouco comum: está crescendo demais." (SOUTO MAIOR, 1996, p.131).
} 
A partir de 1966, por uma estratégia política para viabilizar a emancipação do município, houve um contingente ainda maior de pessoas se dirigindo para Assis.

Para obter criação do novo território, separando-o do território de Toledo ao qual pertencia, houve uma batalha política. Segundo Boritza (2008, p. 23), "[...] o então prefeito do município de Toledo, o Dr. Campanholo, não aceitava a separação [...]” e, por isso, foi necessária a intervenção de uma personalidade muito importante para agilizar os trâmites. Souto Maior (1996, p. 52), menciona que o jornalista Assis Chateaubriand era, "particular amigo" de Oscar Martinez, e que o mesmo facilitaria uma negociação com o governo Estadual da época, o Sr. Paulo Pimentel, para se criar a lei de emancipação do novo município.

O Dr. Francisco de Assis Chateaubriand Bandeira de Mello, era dono de dois canais de televisão e diversos jornais. Só esse fato já bastava para tirar vantagem colocando seu nome no município. A divulgação da criação deste município foi em cadeia nacional. O município começou a aparecer em várias manchetes de jornais brasileiros que publicavam artigos tais como: "Assis Chateaubriand é cidade do Paraná", "Assis Chateaubriand agora é algo diferente", "Acaba de nascer Assis Chateaubriand" (BORITZA, 2008, p. 24)

Por esses motivos é possível entender que não foi por acaso que a cidade de Assis Chateaubriand continuasse atraindo muitos povos e etnias. A partir da criação do município no ano de 1966, o local passou a ganhar um marketing nacional feito pelos meios de comunicação do jornalista que noticiava a façanha de sua honraria recebida em vida, isto é, de ter um município recém-criado com o seu nome.

Tal marketing contribuía para atrair um número grande de pessoas, as quais viam em Assis as oportunidades de fazer aumentar suas posses. Porém, o local também atraia a muitos que desejavam ser incluídos novamente nos meios de subsistência e existência social, através de uma posse de terras em Assis. O trabalhador que migra, nesse caso, segundo Martins (2002) “[...] é a pessoa que está procurando a reinclusão na sociedade através do meio mais seguro para que o expropriado e desenraizado tenha uma inserção estável nas relações sociais.” (2002, p. 121-126).

Assim, muitos desenraizados e excluídos, de várias partes do país, tornaram-se nos primeiros moradores de Assis, os quais formaram não somente a grande população inicial da cidade, mas também o excedente dela, ou seja, aqueles que não encontraram possibilidades reais de obter a posse da terra e permanecer tendo suas condições de vida garantidas. 
Esses muitos que buscavam oportunidades contribuíam para o aumento da população de Assis que, segundo dados estimados do IBGE do ano de $1975^{5}$, chegou a ser em torno de 113 mil habitantes, embora os entrevistados mencionassem que esse número fosse ainda maior.

A maioria dos que chegavam expressava justamente o desejo de obter a posse de terra e, com seu cultivo, se desenvolver e permanecer no município, conforme é demonstrado no gráfico (2) a seguir.

Gráfico 2 - Motivos da vinda para Assis Chateaubriand

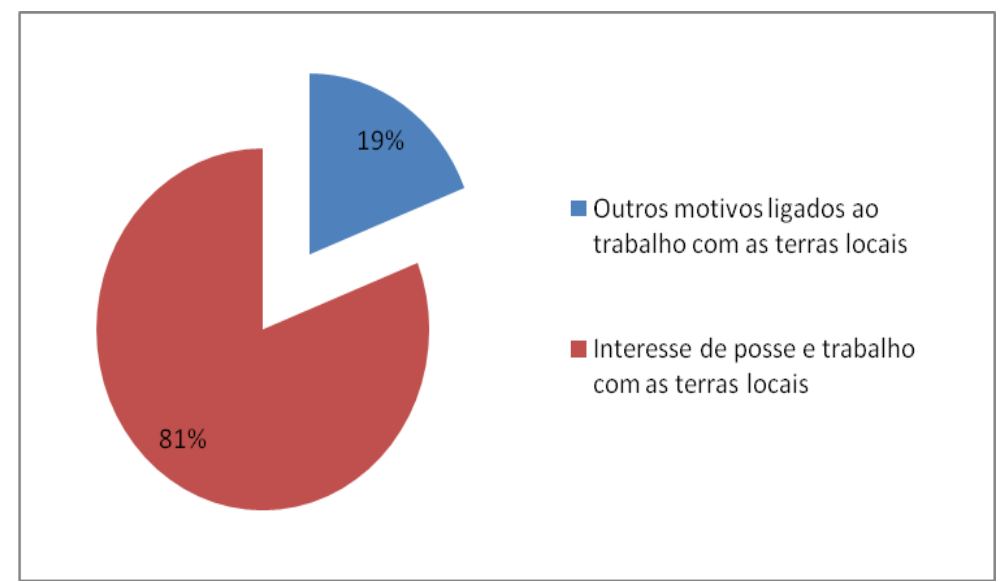

Fonte: Dados de pesquisa do autor (2017)

Porém, a maioria dos novos habitantes não conseguiu obter a posse de terra (Gráfico 3). A lógica da metamorfose da terra em mercadoria, a mesma que teria gerado conflitos entre posseiros, contra a atuação da Colonizadora Norte do Paraná, operava, agora, na fase do comércio para os que detinham condições de compra.

Gráfico 3 - Migrantes que conseguiram comprar terras em Assis Chateaubriand /PR

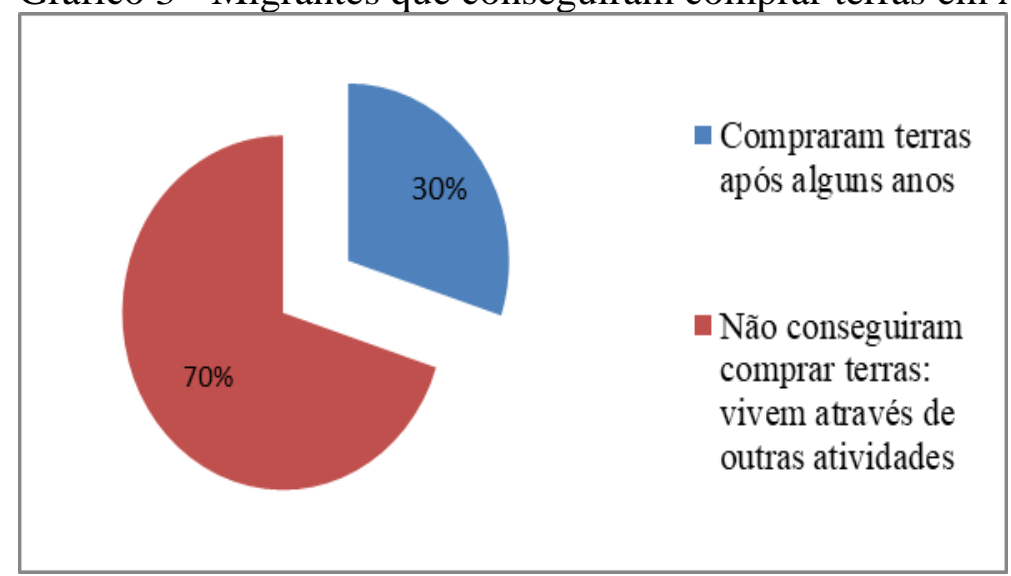

Fonte: Dados de pesquisa do autor (2017)

\footnotetext{
${ }^{5}$ Informação constante em: IBGE. Anuário Estatístico do Brasil, 1976, p. 109 - Estimativa populacional de Assis Chateaubriand $1975 / 76$.
} 
O número grande de pessoas que vieram para Assis carregava a ideologia, ou a promessa de uma chance de melhora nas condições de vida. Porém, uma ideologia pode se apresentar como sendo uma inversão do real, segundo Marx (1996). No caso local, ela surge como uma espécie de ilusão, por meio do marketing feito sobre Assis, o que contribuiu para que muitos acreditassem que havia reais oportunidades para todos em adquirir terras, o que de fato não ocorreu.

Chauí (1997), menciona que a ideologia, muitas vezes, é utilizada para o "ocultamento" ou "dissimulação" do que seria a realidade.

A ideologia, forma específica do imaginário social moderno, é a maneira necessária pela qual os agentes sociais representam para si mesmos o aparecer social, econômico e político, de tal sorte que essa aparência, por ser o modo imediato e abstrato de manifestação do processo histórico, é o ocultamento ou a dissimulação do real. (CHAUÍ, 1997, p. 3-4)

Ainda, Chauí (1997, p. 4) menciona que "a ideologia é aquele discurso no qual os termos ausentes garantem a suposta veracidade daquilo que está explicitamente afirmado".

No caso chateaubriandense, a velocidade da comunicação que divulgava o novo município não era a mesma que, de forma equilibrada, informasse que não seria fácil para todos comprar terra e, por consequência, permanecer no local.

Tal ilusão, portanto, contribuiu para um grande excedente populacional em Assis, isto é, um número grande de muitas famílias que apostaram no município como sendo um local para uma melhor condição socioeconômica, o que de fato não pôde ocorrer.

\section{Os Efeitos da Modernização da Agricultura para d Dinâmica Populacional de Assis Chateaubriand/PR}

Pouco tempo após a emancipação do município, em decorrência da modernização da agricultura, o trabalho braçal começou a se tornar escasso. O novo padrão agrícola de trabalho com as terras, onde as máquinas substituíram a força humana, não contribuiu para a permanência das muitas famílias que migraram para Assis.

Assim sendo, apesar da estimativa do IBGE de que o município viesse a ter mais de 113 habitantes em meados de $1970^{6}$, os censos a partir de 1980 (tabela 2) mostram o contrário do crescimento populacional que se previa. Enquanto o país aumentava em população, Assis apresentava o inverso do esperado, devido à ausência de trabalho.

\footnotetext{
${ }^{6}$ Informação constante em: IBGE. Anuário Estatístico do Brasil, 1976, p. 109 - Estimativa populacional de Assis Chateaubriand 1975 /76
} 
Tabela 2 - População do Brasil e Assis Chateaubriand/PR de 1970 a 2010.

\begin{tabular}{|c|c|c|c|c|c|}
\hline & $\mathbf{1 9 7 0}$ & $\mathbf{1 9 8 0}$ & $\mathbf{1 9 9 1}$ & $\mathbf{2 0 0 0}$ & $\mathbf{2 0 1 0}$ \\
\hline Brasil & 93.134 .846 & 119.011 .052 & 146.825 .475 & 169.872 .856 & 190.755 .799 \\
\hline Assis Chateaubriand/PR & 78.600 & 54.629 & 39.737 & 33.317 & 33.025 \\
\hline
\end{tabular}

Fonte: IBGE, Censos Demográficos de 1970 - 2010

O êxodo causado pela modernização não foi uma exclusividade de Assis Chateaubriand. Tal fato acontecia em escala nacional. Contudo, devido ao grande número de pessoas que para Assis migrou, as consequências para o local foram mais visíveis.

Os dados contados nos censos até 2010 (tabela 3) mostram como o percentual da população urbana no Brasil crescia grandemente, demonstrando a diminuição da população do campo.

Tabela 3 - Aumento da população urbana no Brasil

\begin{tabular}{|c|c|c|}
\hline Ano & Brasil & População urbana(\%) \\
\hline 1970 & 94.508 .583 & 55,9 \\
\hline 1980 & 121.150 .573 & 67,6 \\
\hline 1991 & 146.917 .459 & 75,6 \\
\hline 2000 & 169.590 .693 & 81,2 \\
\hline 2010 & 190.755 .799 & 84,4 \\
\hline
\end{tabular}

Fonte: IBGE, Censos Demográficos 1970 - 2010

A modernização da agricultura, que em Assis se iniciou a partir de 1972, contribuía para a expulsão das pessoas do meio rural.

De acordo com Schallenberger e Colognese (1993, p. 23), “O mercado se encarregou de definir os produtos viáveis, atribuindo-lhes valores convencionais [...]. A terra deixou de ser um espaço social de produção da subsistência e de produção de relações familiares. Assumiu, progressivamente, o caráter de um meio de produção de mercadorias [...]". Essa mudança na agricultura do país passava a influenciar as formas de produção e as relações sociais no campo.

A nova dinâmica da agricultura no Brasil afetava a identidade dos homens que sempre foram da lavoura, obrigando a muitos deixarem o vínculo que possuíam com a terra.

A modernização da agricultura, nos moldes das inovações tecnológicas baseadas na Revolução Verde, repercutiu significativamente no conjunto das 
relações sociais, na cultura e na produção agropecuária do Oeste do Paraná. A vinculação a um novo eixo de decisões aprofundou a dependência e afetou a identidade cultural do homem regional. Essas novas relações competitivas, a especulação imobiliária e financeira e a concentração de propriedade a nível regional, se vincularam aos interesses dos agentes do capital internacional e articularam as suas relações preferenciais não mais com a comunidade, mas com o mercado. (VANDERLINDE; GREGORY; DEITOS, 2007, p. 147).

O vínculo do campo com as inovações tecnológicas, pelo uso das máquinas, gerou grande diminuição da força humana de trabalho no campo.

[...] foi possível a substituição e a redução do uso de mão de obra e o aumento do uso de terra e capital. Os utensílios e equipamentos tradicionais foram perdendo importância e foram sendo substituídos por máquinas e equipamentos considerados essenciais à modernização. Tais mudanças exigiram adaptações e mudanças profundas e violentas do homem rural. (VANDERLINDE; GREGORY; DEITOS, 2007, p. 147)

Brant (1979), também evidencia as mudanças que ocorriam nas relações de trabalho no âmbito da agricultura, mencionando as formas de substituição daqueles que antes eram trabalhadores residentes.

A utilização de força de trabalho assalariada temporária, em substituição à dos trabalhadores residentes, constitui uma das modificações mais importantes nas empresas rurais do Brasil durante os últimos decênios. [...] $\mathrm{O}$ processo de expulsão dos trabalhadores residentes dos estabelecimentos agropecuários ocorreu em algumas regiões independentemente de modificações técnicas no processo produtivo, como simples modificação de relações de trabalho. (BRANT, 1979, p. 67).

A partir da modernização, os que eram proprietários das terras, buscando melhor produção e competitividade, reduziram o trabalho braçal em grande medida, fato que causava, segundo Martine (1987, p. 59), um "grande êxodo em todas as regiões produtivas do Brasil, a partir de 1970".

Além das regiões industrializadas, outras localidades agrícolas também foram o destino de muitos que saíam da região de Assis. Schaefer (1985), menciona o fato de muitas famílias terem saído do Paraná e de outras regiões do sul do Brasil, em meados de 1970, na direção do Paraguai e também Rondônia.

O Paraná está expulsando em massa os pioneiros e seus descendentes para as novas fronteiras agrícolas do Norte e Centro-oeste do país e mesmo para o exterior. O Paraguai é o país que mais recebe imigrantes brasileiros, em sua maioria vindos do interior do Paraná e Santa Catarina, como de outros Estados Brasileiros. Os emigrantes paranaenses estão abandonando aquele Estado após uma colonização rápida e mesmo predatória. [...] tendo este fluxo em direção ao 
país vizinho iniciado em 1968. [...] Trata-se de ex-volantes, meeiros e pequenos proprietários que perderam seu lote. (SCHAEFER, 1985, p. 36).

O autor destaca que os retirantes eram os que "[...] não tinham mais terra ou nunca a tiveram, e não tinham condições de comprar outras [...]. Expulsos pela mecanização de terras no Paraná.” (SCHAEFER, 1985, p. 36).

A modernização também veio contribuir para que muitas pequenas propriedades viessem a desaparecer dando lugar a outras maiores, uma vez que os proprietários das terras menores foram forçados a vender ou a arrendar os seus lotes para outros com poder maior de aquisição e possibilidades de modernização.

Esse fenômeno, segundo Silva (1981), leva o nome de "engolimento" das propriedades, acentuando ainda mais as desigualdades existentes, fazendo com que muitos dos pequenos proprietários de Assis deixassem o campo e se juntassem ao número dos que nunca tiveram a terra.

O gráfico (4) abaixo, demonstra, em percentuais, os motivos apontados pelos entrevistados para a saída da população de Assis para outras regiões.

Gráfico 4 - Motivos da saída da população de Assis Chateaubriand /PR

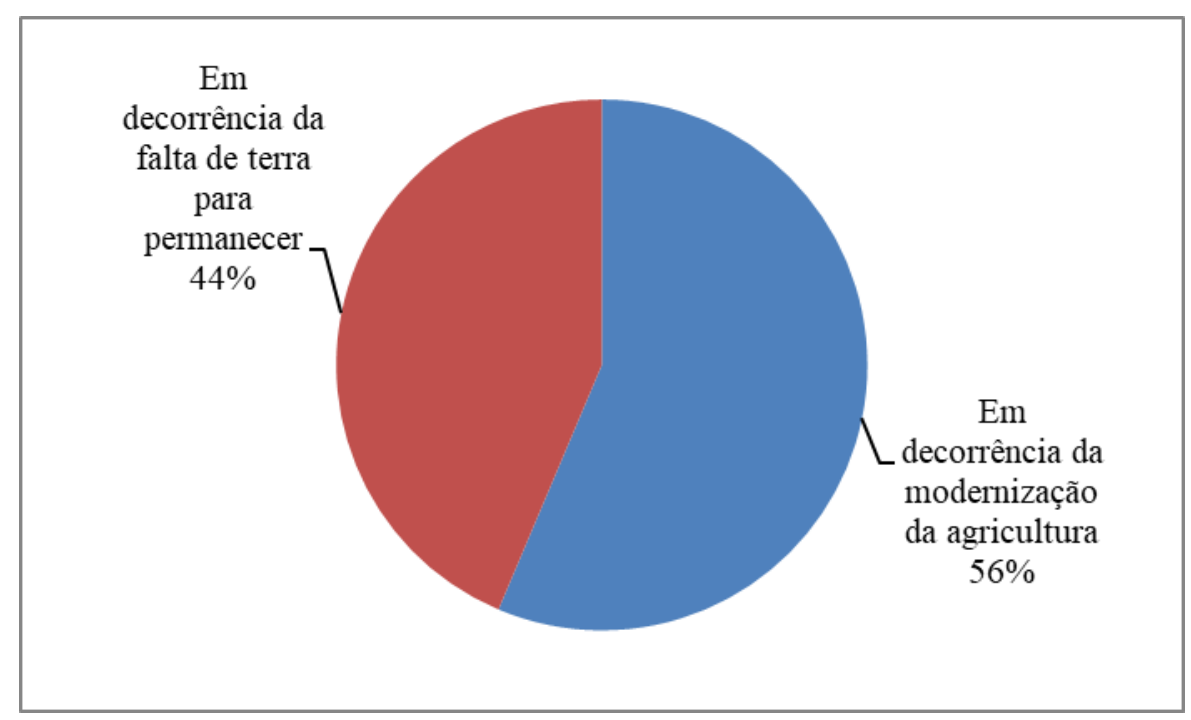

Fonte: dados de pesquisa do autor (2017)

O município de Assis Chateaubriand, que integrava o espaço que ficou conhecido como fronteira agrícola do Oeste do Paraná, uma vez ocupado e colonizado, limitou a possibilidade de um grande excedente populacional às condições de posse da terra. A consequência deste 
fenômeno, somado à modernização da agricultura, fez ocorrer um dos maiores êxodos de habitantes entre os municípios do Oeste do Paraná.

A fotografia abaixo (fotografia 2), mostra um desfile cívico ocorrido na avenida central de Assis Chateaubriand em meados da década de 1970, quando já era possível perceber a presença das máquinas no campo.

Fotografia 2 - Desfile cívico em Assis Chateaubriand na década 1970

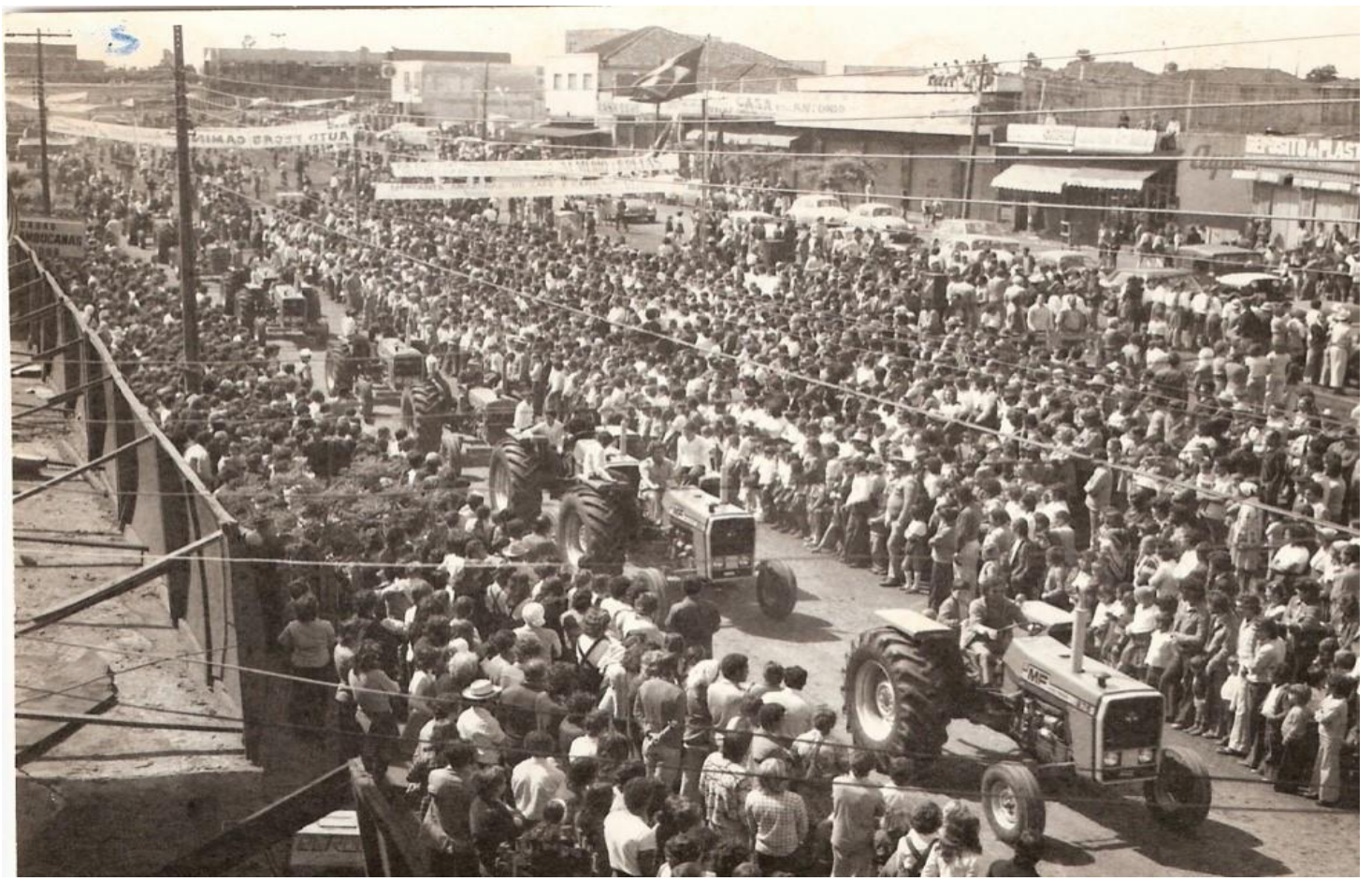

Foto: BRITO [ac.1976]

As pessoas que apreciavam o desfile, provavelmente, sequer imaginavam que aquilo que admiravam seria, também, uma das causas de não poderem permanecer no município, pela progressiva eliminação do trabalho braçal no campo.

\section{Considerações Finais}

Não ter a terra, ou tê-la numa quantidade pequena, ademais dos efeitos da modernização da agricultura, são os elementos fundamentais para o entendimento da expulsão e expropriação de muitos moradores de Assis. Tais fatos ocasionaram condições não sustentáveis e, consequentemente, de obrigatória saída de grande parte dos que compuseram o território chateaubriandense na sua origem. 
O crescente refluxo populacional ocasionado, por assim dizer, foi possível graças ao grande fluxo de pessoas que se dirigiu ao território do município em seu início, atraído pelo marketing sobre a terra local e pela possibilidade de se viver a partir da posse da mesma.

Contudo, não havendo outras formas de subsistência, as quais fossem suficientes para absorver tão grande número de pessoas expulsas ou expropriadas do campo, a melhor e mais viável opção para cerca de três quartos da população inicial do município, foi a de novamente migrar, para outras localidades agrícolas do país, ou para centros urbanos industrializados e com maiores chances de trabalho. Hoje, a cidade de Assis Chateaubriand, possui cerca de 34.000 habitantes.

\section{BIBLIOGRAFIA}

BALÍCIO, Olívio. [S.t.]. [Entrevista cedida a] PARANÁ: A OCUPAÇÃO DA TERRA. [S. 1.: s. n.], 2013. 1 vídeo (13 min). Publicado por José Pardinho de Souza. Disponível em: <https://www.youtube.com/watch?v=F_HUc1p9VD0>. Acesso em: 22.06.18

BORITZA, Rita. Assis Chateaubriand: História e memória. Produção Didático-pedagógica Caderno Temático. Marechal C. Rondon: PDE, 2008.

BRANT, Vinícius Caldeira. População e Força de trabalho no desenvolvimento da agricultura brasileira. São Paulo: CEBRAP, 1979.

BRASIL. Lei $n^{\circ} 2.597$ - 05 de Setembro de 1955. Dispõe sobre zonas indispensáveis à defesa do país. Disponível em: <http://www.planalto.gov.br/ccivil_03/leis/1950-1969/L2597.htm>. Acesso em: 20 de março de 2018.

BRITO, Ademir de. [S.t.]. [ca. 1968]. 1 fotografia.

$$
\text { [S.t.]. [ca. 1976]. } 1 \text { fotografia. }
$$

BUKOSKI, Augustinho. [S.t.]. [Entrevista cedida a] PARANÁ: A OCUPAÇÃO DA TERRA. [S. 1.: s. n.], 2013. 1 vídeo (13 min). Publicado por José Pardinho de Souza. Disponível em: <https://www.youtube.com/watch?v=F_HUc1p9VD0>. Acesso em: 22.06.18

CAPRA, Frritjof. A teia da vida. Uma nova compreensão científica dos sistemas vivos. São Paulo: Cultrix, 1996.

COLOGNESE, Silvio A. e outros. Tupãssi: do mito à História. Cascavel: Edunioeste, 1999.

CHAUÍ, Marilena. O que é ideologia. São Paulo: Brasiliense, 1997.

CRESTANI, Leandro de Araujo. Conflitos agrários e mercado de terras nas fronteiras do Oeste do Paraná (1843/1960). [Dissertação de Mestrado em Desenvolvimento Regional e Agronegócio] Toledo: UNIOESTE, 2012.

DANTAS, Eugenia Maria. Geografia da população / Eugenia Maria Dantas, Ione Rodrigues Diniz Morais e Maria José da costa Fernandes. - 2a ed. - Natal: EDUFRN, 2011.

FERNANDES, Florestan. Mudanças sociais no Brasil; apresentação de Marco Antonio Villa. $4^{\text {a}}$ ed. rev. São Paulo: Global, 2008. 
IANNI, Octavio. Origens Agrárias do Estado Brasileiro. São Paulo: Brasiliense, 2004.

IBGE - INSTITUTO BRASILEIRO DE GEOGRAFIA E ESTATÍSTICA. Anuário Estatístico do Brasil, Rio de Janeiro: IBGE, 1976.

IBGE - INSTITUTO BRASILEIRO DE GEOGRAFIA E ESTATÍSTICA. Censos Demográficos, 1970 - 2010. Disponível em: <https://www.ibge.gov.br/cidades-eestados.html?view=municipio>. Acesso em: 20 de outubro de 2018.

LEITE JÚNIOR, Hor-Meyll Teixeira; ESCUBEDO, Marcel Luz. Moisés Lupion: Civilizador do Paraná. Curitiba: Imprensa Oficial, 2006. (Vol.1).

MARTINE, George. Os impactos sociais da modernização agrícola. São Paulo: Hucitec, 1987.

MARTINS, José de Souza. Exclusão Social e a nova desigualdade. 3.ed. São Paulo: Paulos, 1997.

A sociedade vista do abismo: novos estudos sobre exclusão, pobreza e classes sociais. Petrópolis: Vozes, 2002.

MARX, Karl. A ideologia alemã. São Paulo: Hucitec, 1996.

MUNDO EDUCAÇÃO. Revolução Verde. Disponível em: <http://mundoeducacao.bol.uol.com.br/geografia/a-revolucao-verde.htm> Acesso em: 23 de Fevereiro de 2017.

OLIVEIRA, Ariovaldo Umbelino de. A geografia das lutas no campo. $13^{\mathrm{a}}$ ed. - São Paulo: Contexto, 1990.

PAZ, Francisco Moraes. Cenários de economia e política: Paraná / Francisco Moraes Paz (organizador) - Curitiba: Prephacio, 1991.

PIRES, Orlando José. [S.t.]. [Entrevista cedida a] PARANÁ: A OCUPAÇÃO DA TERRA. [S. l.: s. n.], 2013. 1 vídeo (13 min). Publicado por José Pardinho de Souza. Disponível em: <https://www.youtube.com/watch?v=F_HUc1p9VD0>. Acesso em: 22.06.18

PRADO JÚNIOR, Caio. História econômica do Brasil. São Paulo: Brasiliense, 2012.

ROSS, Jurandyr Sanches. Geografia do Brasil. - $5^{\text {a }}$ ed. rev. e ampl. - São Paulo: Editora da Universidade de São Paulo, 2005.

SANTOS, Maria Cristina Ferreira dos. A guerra do Contestado: desfazendo as armas do esquecimento. Revista eletrônica de crítica e teoria de literaturas. Porto Alegre: PPG-LETUFRGS. vol.6 n.1, Janeiro/Junho 2010.

SCHAEFER, José Renato. As migrações rurais e implicações pastorais: um estudo das migrações campo-campo do sul do país em direção ao norte do Mato Grosso. São Paulo: Edições Loyola, 1985.

SCHALLENBERGER, Erneldo. \& COLOGNESE, Silvio Antônio. Migrações e comunidades cristãs no sul do Brasil. Toledo, PR: Unioeste/Facitol, 1993.

SILVA, José Graziano da. A modernização dolorosa: Estrutura agrária, fronteira agrícola e trabalhadores rurais no Brasil. Rio de Janeiro: Zahar Editores, 1981.

SOUTO MAIOR, Laércio. História de Assis Chateaubriand: o encontro das correntes migratórias na última fronteira agrícola de Estão do Paraná. Maringá: Clicheter, 1996. 
VANDERLINDE, Tarcísio. Migrações e a construção do Oeste do Paraná: Século XXI em perspectiva / Organização de Tarcísio Vanderlinde, Valdir Gregory, Nilceu Jacob Deitos. Cascavel: Coluna do Saber, 2007.

Recebido em 10/06/2019 - Aprovado em 30/07/2019. 